\title{
On the Long-Run Interdependence of Stock Markets: A Tale of Correlations, Auto- regressions and Decompositions
}

\section{Elna Moolman}

Department of Economics, University of Pretoria

\section{Suzanne McCoskey}

University of Pretoria and the United States Naval Academy

\section{ABSTRACT}

It seems as if national stock markets within certain groups of countries, for example within Europe and Asia, are interdependent. But to what extent are stock markets between these groups interdependent? Is it still possible to diversify among these groups, or have globalization tied world markets together to such an extent that diversification is no longer feasible? In this study we use time series techniques to analyze the interdependence among four of the most important groups of economies, namely Europe, Latin America, Asia and the US. This will show whether it is still possible to diversify between the stock markets of these groups of economies, since stock markets within these groups seem to be interdependent to such an extent that diversification within these groups is no longer possible. On a methodological level, we compare the results of the OLS-VAR with an FM-VAR model, which is a more robust estimation procedure in the presence of non-stationary or cointegrated series.

JEL F02, F36, G10

\section{INTRODUCTION}

Portfolio theory suggests that investing in less than perfectly correlated asset markets will result in greater diversification effects. This resulted in a search for diversification gains, which has been aggressively extended in investing internationally in the hope of additional diversification. In the mean time, financial globalization caused revolutionary and irreversible changes in financial markets. International capital transactions have accelerated, and innovations and deregulation have changed financial market structures. More instruments and markets have developed, and technological development has made a portfolio comprising international assets universal (Handley \& Mills, 1996: 74). The ongoing relaxation of foreign investment restrictions and foreign exchange 
controls in many countries has led to the speculation that world equity markets have become more integrated than ever, and that the diversification gain from investing internationally might have been reduced significantly.

This calls for an examination of the intermarket relationships and dynamic linkages between international stock markets as the interdependence structure has important implications for market efficiency, profitable investment opportunities, risk diversification and international policy co-ordination. If markets are inefficient, the transmission of shocks from one market to another will involve systematic lagged responses that may be exploited by informed investors. On the other hand, lack of interdependence among markets will engender opportunities for risk diversification.

Many studies have been conducted on the interdependence of different national stock markets, using different econometric techniques. For example, Masih and Masih (1997, 1999), Chowdhury (1994) and Palac-McMiken (1997) analyzed the interdependence among Asian markets while Dheeriya (1993) and Choudhry (1996) analyzed interdependence in Europe, and Christoffi and Pericli (1999) and Choudhry (1997) analyzed interdependence among Latin American markets.

Stock market interdependence in the emerging markets in Asia seems to be a widely accepted fact. Masih and Masih (1999) examined relationships among the stock markets of Thailand, Malaysia, the US, the UK, Japan, Hong Kong and Singapore from 1992 to 1997 . The most important finding of their study is that Asian stock market fluctuations are mostly explained by the regional markets, rather than by the developed markets. They found that these markets are cointegrated, and their vector error correction modeling (VECM), variance decomposition and impulse response functions confirmed a high level of interdependence between these markets. Masih and Masih (1997) used the same econometric techniques, but a different group of Asian markets and data for the period 1982 to 1994 . Consistent with their later findings (Masih \& Masih, 1999), they found cointegration among the markets of Taiwan, South Korea, Singapore, Hong Kong, the US, the UK, Germany and Japan. Again, their VECM, variance decomposition and impulse response functions confirmed a high level of stock market interdependence.

Other authors examined different groups of Asian markets, but their results are consistent with those of Masih and Masih $(1997,1999)$ since they all found their respective stock market groups to be interdependent. Palac-McMiken (1997) found cointegration in the monthly ASEAN markets (Indonesia, Malaysia, the Philippines, Singapore and Thailand) during the period 1987 to 1995. Chowdhury (1994) used variance decomposition and impulse response functions 
to examine the relationships among Hong Kong, Korea, Singapore, Taiwan (that is, the Asian Newly Industrialized Economies (NIEs)), Japan and the US, using daily data for the period January 1986 to December 1990 . He found that the US led the NIEs and that there were significant linkages between the markets. In general, these studies used different techniques and different sample periods, but they all found that the emerging Asian markets are interdependent.

Although there is substantially less literature on stock market interdependence in the emerging Latin American markets, all the available results indicate that the stock markets in this region are also interdependent. Christofi and Pericli (1999) used a vector autoregressive (VAR) model in their study on the stock markets of Argentina, Brazil, Chile, Columbia and Mexico from 1992 to 1997. They found significant spillover effects among these Latin American markets. Choudhry (1997) investigated interdependence among the stock markets of Argentina, Brazil, Chile, Colombia, Mexico and Venezuela, and by using cointegration techniques, found a common stochastic trend in these markets. Therefore, consistent with the results of the emerging Asian markets, the emerging Latin American markets are found to be interdependent.

In a study on European stock prices, Choudhry (1996) used cointegration techniques to analyze the long-run relationships, which should indicate the presence of common stochastic trends among indices. He used monthly data for the 1920 s and 1930s of Czechoslovakia, France, Italy, Poland, Spain and Sweden. His results indicate a stationary long-run relationship during 1925-1936 and also during the pre-1929 crash period (1925-1929), but not during the postcrash period (1929-1936).

Dheeriya (1993) used Geweke's causality test to study the direction of causality and feedback between the stock markets of Australia, Austria, Belgium, Canada, Denmark, France, Germany, Ireland, Italy, Japan, Netherlands, Norway, Spain, Sweden, Switzerland, the UK and the US, by using daily data for 1987 and 1988. The impact of the stock market crash of October 1987 on other national stock markets is investigated by disaggregating the data into pre- and post-crash periods. His results showed that almost all markets react to other markets' past and present movements. However, very few stock markets (only the US and UK) influenced other markets significantly, and the traditionally major markets of Japan, France and Canada, did not seem to be influential at all.

From the literature it seems as if stock markets of countries within certain groups, for example within Europe, Latin America and Asia are interdependent. For example, Masih and Masih (1997, 1999) and Palac-McMiken (1997) detected interdependence among certain Asian stock markets, Chowdhury (1994) found interdependence among certain European stock markets and 
Christoffi and Pericli (1999) indicated interdependence among Latin American stock markets. But to what extent are stock markets within these groups interdependent? The results suggest that the gains from diversification within these groups of countries have decreased significantly. Is it then still possible to diversify among these groups, or are they so interrelated that diversification is no longer feasible?

In this study we analyze the interdependence among some of the well-known groups of economies, namely Europe, Latin America, the US and Asian economies. This will show whether it is still possible to diversify between the stock markets of these groups of economies, since stock markets within these groups seem to be interdependent to such an extent that diversification within these groups is no longer possible.

We use time series techniques to address several important issues regarding the long-term relationships among major stock market groups. In particular, we use Granger causality tests, vector autoregressive (VAR) analysis, impulse response functions and variance decompositions. The first issue is quite simply whether a direction of causality can be determined amongst the different groups of stock exchanges. This issue is addressed through tests for Granger causality, which test the null hypothesis that one stock market does not Granger cause another stock market. This test is conducted for every possible combination of stock markets, in every possible direction of causality to determine between which stock markets there is causality and in which direction. Secondly, it can be asked whether the stock markets inform forecasts of other stock markets. For this variance decompositions can be used, which describe the proportion of the forecast error variance that can be explained by each stock market including the stock market itself. If almost all the forecast error variance is explained by innovations in the series itself, the series is largely exogenous. This would indicate that the particular stock market is not interdependent on the other markets, but is determined exogenously. On the other hand, if a substantial part of the forecast error variance of a series is explained by innovations in other series, it suggests that the variable is not exogenous but interrelated with the other markets.

Thirdly, we use vector autoregression (VAR) analysis to analyze the dynamic interactions among the markets. We will initially estimate the VAR model with ordinary least squared (OLS), and then check these results against that of an FM-VAR estimation, which is a more robust estimation procedure in the presence of non-stationary and cointegrated series. If dynamic interactions are found, impulse response functions can be used to track the length of the dynamic shocks to the system. 
The article is outlined as follows: Section 2 summarizes the data and section 3 explains the theory of stock market interdependence. Section 4 summarizes the time series techniques used in the study. The empirical results are given in section 5 , and section 6 provides some concluding thoughts.

\section{THE DATA}

It is a well-known fact in econometrics that the span of the data, and not the frequency, should be taken into account when looking at long-term trends (Hatanaka, 1996: 25). By using annual data for a relatively long period - 34 years instead of 1 or 2 years like most of the studies - we are able to look at long-run trends instead of short-run fluctuations, which may not be persistent or may reflect special circumstances. The long span of the data also makes it possible to compare performance over a number of market cycles.

We use the stock market indices of 4 of the major groups of countries, namely Europe, the US, Latin America and the Asian economies. The Standard and Poor 500 index is used to represent the US stock market index. The indices of the United Kingdom, Germany, France, Italy, Switzerland, Netherlands, Belgium, Spain, Denmark, Norway and Sweden are included in the European index. The Latin American index includes Argentina, Brazil, Chile, Columbia, Mexico, Peru and Venezuela and the Asian index includes Hong Kong, India, Israel, Malaysia, Pakistan, Philippines, Singapore, South Korea and Taiwan. These aggregated indices were obtained from Global Financial Data (http://www.globalfindata.com). In order to make the indices directly comparable, all the indices are measured in US dollars. The indices are capitalization-weighted annual stock price indices for 1919 - 1999 (except for Latin America and Asia where data was only available since 1936 and 1967 respectively), with 1969 as the base year.

By looking at the graphs of the composite indices in Figure 1, several broad patterns cmerge. In general, there has been a significant increase in all the indices since the globalization of the nineties. However, the US and European indices show a steady increase while the Asian and Latin American indices were extremely volatile during their increases. When the US is compared with Europe, the difference is relatively small, except for a slightly larger gap during the period 1982 to 1992 . Similarly, there has been a remarkable co-movement between the Latin American indices. 
Figure 1 Stock market indices of Asia, Europe, Latin America and the US

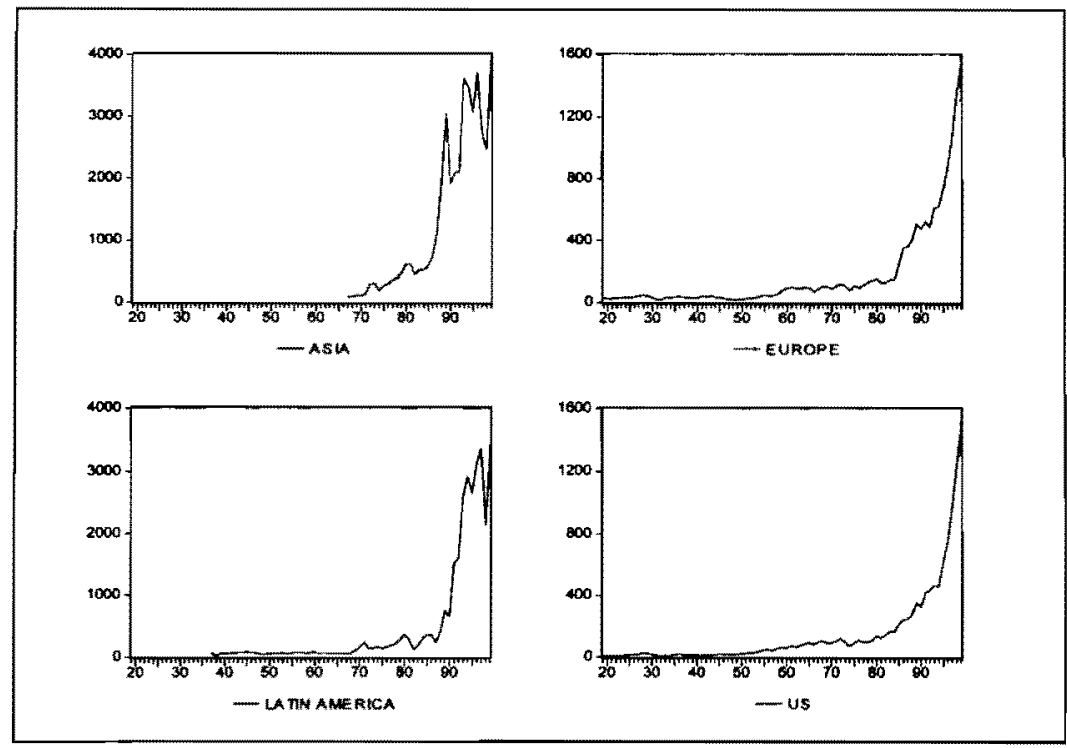

The simple correlations between these groups (see Table 1) suggest very high correlations between these groups. It also shows very high correlation between the relatively undeveloped stock markets of Asia and Latin America, and between the developed stock markets of the US and Europe.

Table 1 Correlations between stock market groups, 1967-1999

\begin{tabular}{|l|c|c|c|c|}
\hline & Asia & Europe & Latin America & US \\
\hline Asia & 1.000000 & 0.859554 & 0.912211 & 0.801067 \\
\hline Europe & 0.859554 & 1.000000 & 0.885803 & 0.990116 \\
\hline $\begin{array}{l}\text { Latin } \\
\text { America }\end{array}$ & 0.912211 & 0.885803 & 1.000000 & 0.865556 \\
\hline US & 0.801067 & 0.990116 & 0.865556 & 1.000000 \\
\hline
\end{tabular}

\section{THEORETICAL EXPLANATION OF STOCK MARKET INTERDEPENDENCE}

In general, there are three categories of explanations as to why there is comovement among different stock markets. The first category is the so-called 
contagion effect, which is the part of stock market co-movement that cannot be explained by economic fundamentals. The second category is economic integration, which means that the more the economies of two countries are integrated, the more interdependent or integrated their stock markets will be. Economic integration includes not only trade relationships, but also comovement in the economic indicators that influence stock market returns, such as interest rates and inflation. The third and last category includes stock market characteristics that influence the extent of stock market interdependence, namely industrial similarity, volatility and market size. In general, therefore, the extent of interdependence between two stock markets (or groups of stock markets) should be a function of the following variables:

\subsection{Contagion}

Contagion, as defined by the academic profession, is the co-movement of asset markets not caused by a common movement of fundamentals (Wolf, 1998: 220). Contagion is not measurable in itself, but rather estimated with the residual from the co-movement that is not explained by fundamentals. There are two broad categories of literature on this field, either based on informational factors or based on institutional factors (op. cit: 220). The category of informational factors is based on the well-known comparison between the stock market and the Keynesian "beauty contest", where each judge votes the way he thinks the other judges will vote. In the same way, investors will sell their investments in a specific asset class if they believe that other investors will sell their investments in that asset class. This provides some explanation of the herd behavior of stock market traders which leads to a sell-off of emerging market securities if a sufficient number of investors believe that other investors have become disenchanted with the emerging markets asset class. The herd behavior of investors will lead to a widespread decline or upswing in emerging markets, and if this widespread movement is not caused by fundamentals, it is, by definition, contagion.

The category of institutional factors focuses on issues such as forced redemption and two-stage investment strategies (op. cit.: 221). A substantial proportion of the inflows to the equity markets of emerging countries come through openended mutual funds. When these funds are faced with large-scale withdrawals or a reduction in inflows, they may be forced into redemption. Global mutual funds will then sell off their assets in the most liquid markets. In other words, if these markets were not affected previously, they will be affected by the forced redemption. This redemption thus creates a contagion effect in which several markets decline simultaneously without justifying changes in fundamentals. The same occurs when global mutual funds try to exploit perceived mispricing via 
purchases in the most downtrodden markets, financed through sales of equities in less-affected markets (op. cit.: 221).

With two-stage strategies, some fraction of the overall portfolio is allocated to the emerging-market category, and is then sub-allocated according to some index weighting. This provides the second of the institutional explanations for contagion to the extent that first-stage decisions, even if motivated by factors relevant to some emerging markets, may also affect markets for which these factors are of little importance (Chuhan, 1994).

\subsection{Economic Integration}

From a macroeconomic perspective, there are two broad categories of economic variables that influence the degree of stock market interdependence, namely the extent of bilateral trade and factors that influence stock prices according to the cash flow model.

\subsubsection{Bilateral trade}

When two countries have a strong bilateral trade relationship, their economies and stock markets are expected to be highly interdependent. If a substantial portion of country A's total exports are exported to country B, then a downswing in country $B$ will cause a decline in its imports from country A. There will be a decline in country B's stock market associated with the domestic downswing in country $B$, and at the same time a decline in country A's stock market due to the reduction in exports to country $B$. The stock markets of the two countries will thus exhibit a co-movement due to their bilateral trade ties. The more important the trade ties, the higher the degree of co-movement in the stock markets. Therefore, the bilateral trade relationship between two countries is expected to explain some of the correlation or co-movement between their stock markets.

\subsubsection{The cash flow model}

Stock prices (P) can be written as the expected discounted stream of dividends:

$P=\frac{E(c)}{k}$

where $\mathrm{c}$ is the dividend stream and $\mathrm{k}$ is the discount rate. It follows trivially that the systematic forces that influence stock prices, and hence returns, are those that influence the discount factors, $k$, or the expected cash flows, $E(c)$ (Chen et al. 1986). Any factor that influences the stream of cash flows or the discount 
rate will systematically influence stock prices. Since the seminal article by Chen et al. (1986), the influence of interest rates and inflation on the discount rate, and of industrial production growth on the expected cash flows - and hence on stock prices - has been well established.

These macroeconomic variables influence the stock market performance of an individual country, which means that in two countries in which these variables are similar, the stock market performance will be similar. For example, if the interest rates of two countries show the same trend over time, perhaps due to similar monetary policies, the effect of interest rates on stock prices will cause a co-movement in the two stock markets. Therefore, larger interest rate, growth and inflation differentials will cause a smaller amount of co-movement.

\subsection{Stock Market Characteristics}

Apart from the economic variables discussed in the previous section, several other variables have been discussed in the literature as having the potential to influence the extent of stock market correlation. These factors are stock market size, stock market volatility and industrial similarity.

\subsubsection{Size}

The effect of the size of a firm on its stock market performance is a welldocumented phenomenon (see for example Banz, 1981; Berk, 1996; Keppler \& Traub, 1993; Asness et al., 1996). Smaller firms command higher returns due to less liquidity and the higher transaction costs associated with trading their equity. By extension, the size of a national equity market may reflect its stage of development, and may also indicate the degree of market liquidity and the level of information cost and transaction cost associated with trading equity in that market. From this perspective, a large disparity in market sizes may indicate large differences in the liquidity, information costs and transaction costs between the two markets, which should result in less co-movement.

\subsubsection{Volatility}

The basic principle on which all investment models are based is that the returns on any asset should be a positive function of its risk. According to the capital asset pricing model (CAPM) of Sharpe (1964) and Lintner (1965), stock market returns should be a positive function of the risk of the stock market, where risk is measured as the volatility or variance of the returns. Since the returns of any stock market are a function of its volatility, two markets with more or less the same volatility should be more interdependent than two markets with substantially different volatilities. 


\subsubsection{Industrial similarity}

The effect of industrial similarity on stock market correlation has received a substantial amount of attention in the literature (e.g. Serra, 2000; Wolf, 1998; Roll, 1992). The performance of any index is partly determined by sectoral composition, and partly obscured by idiosyncratic noise (Wolf, 1998: 224). For example, consider two emerging market indices dominated by equities in a single sector, say petroleum. A decrease in the world demand for oil may lead to a substantial decrease in the equity prices of oil companies in both economies. Thus, when two markets are both dominated by the same type of industry, their stock markets will reveal co-movement to the extent that the general performance of their stock markets is based on that industry. This does not only happen in the extreme case when two markets are dominated by the same sector, but also the extent of industrial similarity between the two stock markets generally increases the extent of their co-movement.

A priori theory therefore suggests the following about the relevant variables and their coefficients:

Interdependence $=f\{$ Trade, inflation differential, interest rate differential, size

differential, volatility differential, growth differential, industrial similarity\};

(i) Trade: The more important the trade relationship between two countries, the more correlated their stock markets should be.

(ii) Inflation differentials: Since inflation influences stock prices, the inflation differential of two countries is expected to influence the extent of interdependence between their stock markets negatively. The bigger the inflation differential, the bigger the difference in stock prices will be, and hence the lower the level of interdependence between the markets.

(iii) Industrial production growth: Industrial production growth influences stock market behavior through the cash flow model, and therefore the difference between two countries' industrial production growth rates will be negatively correlated with the extent of their stock market correlation.

(iv) Interest rates: Interest rates influence the discount factor of the cash flow model and hence stock prices. Therefore, the interest rate differential between two countries should be negatively correlated with their stock market correlation.

(v) Size: Since the size of a stock market reflects its liquidity and transaction costs and therefore influences stock prices, the size difference between any countries' stock markets will have a negative relationship with the correlation of their stock markets. 
(vi) Volatility: The risk of a stock market is measured by its volatility, and stock prices are positively influenced by volatility since investors demand higher returns for tolerating higher risk. This means that in two stock markets whose volatilities converge (diverge), the prices should also converge (diverge). Therefore, the correlation between two stock markets should be a negative function of the ratio of their volatilities.

(vii) Region: Stock markets within a region can be interdependent due to policy coordination, or simply due to contagion caused by investors" treatment of the asset markets within a region as one asset class. Therefore, the correlation between two countries that are in the same region is expected to be higher than that of two countries in different regions.

\section{TESTING METHODOLOGY}

\subsection{Granger Causality}

$Y_{t}$ causes another time series $X_{t}$ in the Granger sense if series $X_{t}$ can be predicted better by using past values of series $Y_{t}$ than by using only the historical values of series $X_{1}$. To test whether $Y_{1}$ Granger causes $X_{t}$, Granger (1969) proposed the following regression equation:

$$
\Delta X_{t}=c_{o}+\sum_{i=1}^{m} d_{i} \Delta Y_{t-i}+\sum_{j=1}^{m} c_{j} \Delta X_{t-j}+v_{t}
$$

where $m$ is the appropriate autoregressive lag length as determined by the Akaike and Schwartz criteria, and $v_{1}$ is white noise. The test for Granger causality is testing the null that $Y_{1}$ does not Granger cause $X_{t}$, by comparing the following F-statistic to the relevant critical values of the $F(m, T-2 m-1)$ distribution:

$$
F=\frac{\left(\mathrm{SEE}_{R}-\mathrm{SSE}_{\mathrm{u}}\right) / \mathrm{m}}{\mathrm{SSE}_{1} /(\mathrm{T}-2 \mathrm{~m}-1)}
$$

where $S S E_{R}$ is the sum of squared residuals from a restricted regression equation, in other words no lagged $Y_{1}$ in equation $X, S_{S E}$ is the sum of squared residuals from equation $X$, and $T$ is the number of observations. 


\subsection{Vector Autoregressive Analysis (VAR)}

The VAR modeling technique is an effective means of characterizing the dynamic interactions among economic variables by reducing dependence on the potentially inappropriate theoretical restrictions of structural models. The general VAR specification can be written as:

$$
X_{1}=A_{0}+A_{1} X_{1-1}+A_{2} X_{1-2}+\ldots+A_{p} X_{1-p}+e_{t}
$$

where $X_{t}$ is a $(n \times 1)$ vector containing each of the $n$ variables included in the VAR

$A_{0}$ is a $(n \times 1)$ vector of intercept terms

$A_{i}$ is a $(n \times n)$ matrix of coefficients

$e_{t}$ is $a(n \times 1)$ vector of error terms

The t-statistic computed for the coefficients of each of the lagged variables indicate whether that particular lagged variable is significant in explaining some of the variation in the relevant dependent variable. Since only lagged values of the endogenous variables appear on the right-hand side of each equation, there is no issue of simultaneity, and OLS is generally regarded as an appropriate estimation technique. However, although OLS is consistent, it may be biased. As described by Phillips (1995), fully modified (FM) estimation of the VAR model should improve the OLS results in the presence of non-stationary regressors, I(I) processes and even cointegrating relationships. In addition, the FM-estimation procedure is valid without pre-testing for the exact cointegrating relationships or even the number of unit roots in the system. The FM-procedure specifically takes into account the possible serial correlation and endogeneities of the system. In this study, we will initially estimate the VAR model with OLS, and then use the FM-VAR procedure outlined by Phillips (1995) to verify its robustness.

\subsection{Impulse Response Functions}

Impulse response functions characterize the dynamic structure of the estimated model by showing how each endogenous variable responds over time to a shock in that variable and in every other endogenous variable. It traces the effect of a one standard deviation shock to one of the innovations on current and future values of the endogenous variables, in other words, it trades the response of the endogenous variables to such shocks (Pindyck \& Rubinfield, 1991: 385). In other words, it can be used to analyze the persistence of shocks in the system, as 
well as the return of the variables to equilibrium levels after shocks in the system.

In the same way that a autoregressive (AR) process can be written as a moving average (MA) process, a vector autoregressive (VAR) model can be written as a vector moving average (VMA). For example, equation $X$ can be written as

$$
X_{1}=\mu+\sum_{i=0}^{\infty} \Phi_{i} \varepsilon_{t-i}
$$

where $\phi_{\mathrm{s}}=\frac{\partial \mathrm{X}_{\mathrm{i}+\mathrm{s}}}{\partial \mathrm{e}_{\mathrm{i}}{ }^{\prime}}$ and $\left(\phi_{\mathrm{s}}\right)_{\mathrm{ij}}=\frac{\partial \mathrm{X}_{\mathrm{i}, 1+\mathrm{s}}}{\partial \mathrm{e}_{\mathrm{jt}}}$.

A plot of $\left(\phi_{\mathrm{s}}\right)_{\mathrm{ij}}$ as a function of $\mathrm{s}$ is called the impulse response function, and it describes the response of $y_{i, t+5}$ to a one-time impulse in $y_{j t}$ with all other variables dated t or earlier held constant (Hamilton, 1994: 319).

\subsection{Variance Decomposition}

Impulse response functions trace the effect of a shock to an endogenous variable on the variables in the VAR. By contrast, variance decomposition decomposes variation in an endogenous variable into the component shock to the endogenous variables in the VAR. Therefore the variance decomposition gives information about the relative importance of each random innovation to the variables in the VAR, by showing the proportion of the movements in a sequence resulting from its own shocks versus shocks to the other variables (Enders, 1995: 311, Pindyck \& Rubinfield, 1991: 385). The s-period head forecast error is:

$$
x_{t+s}-\hat{x}_{t+s \mid t}=\sum_{i=0}^{s-1} \phi_{i} e_{t+s-i}
$$

The mean squared error of this s-period-ahead forecast is:

$$
\begin{aligned}
\operatorname{MSE}\left(\hat{x}_{t+t_{j}}\right) & =\Omega+\Phi_{1} \Omega \Phi_{1}^{\prime}+\ldots+\Phi_{s-1} \Omega \Phi_{s-1}^{\prime} \\
& =\sum_{j=1}^{s}\left\{\operatorname{Var}\left(u_{j t}\right) \times\left[a_{j} a_{j}^{\prime}+\Phi_{1} a_{j} a_{j}^{\prime} \Phi_{1}^{\prime}+\ldots+\Phi_{j} a_{j}^{\prime} \Phi_{s-1}^{\prime}\right]\right\}
\end{aligned}
$$

where $\Omega=E\left(e_{l} e_{t}\right)$, the contribution of innovation $\mathrm{j}$ to the MSE of the forecast error, in other words the proportion of the variance of the s-period ahead forecast of $y$ due to variable $j$, is:

$$
\operatorname{Var}\left(u_{j k}\right) \times\left[a_{j} a_{1}^{\prime}+\Phi_{1} a_{j} a_{j}^{\prime} \Phi_{1}^{\prime}+\ldots+\Phi a_{j} a_{j}^{\prime} \Phi_{s-1}^{\prime}\right]
$$




\section{EMPIRICAL RESULTS}

\subsection{Granger Causality}

F-tests for Granger causality address the question of causality and its direction. In each case a lag order of 2 was allowed, and the test was performed for the period 1967-1999. The results are given in Table 2.

Table 2 F-tests for Granger causality, 1967-1999, 2 lags

\begin{tabular}{|l|c|c|c|c|}
\hline & Asia & Europe & $\begin{array}{c}\text { Latin } \\
\text { America }\end{array}$ & Us \\
\hline Asia & & $8.04705^{* * *}$ & $4.65389^{* *}$ & $3.72338^{* *}$ \\
\hline Europe & 2.39163 & & $3.78015^{* *}$ & $4.08371^{* *}$ \\
\hline Latin America & $4.62679^{* *}$ & $3.62351^{* *}$ & & $5.23372^{* *}$ \\
\hline US & $4.26565^{* *}$ & 1.32013 & $3.24299^{*}$ & \\
\hline
\end{tabular}

* Statistically significant on $10 \%$ level

** Statistically significant on $5 \%$ level

*** Statistically significant on $1 \%$ level

The F-statistic in each cell in Table 2 represents tests of the null hypothesis that the country in that column does not Granger cause the stock markets in that row. For example, the F-statistic of the test that the Asian stock market group does not Granger cause the European stock market group is 2.39163 , while the Fstatistic of the test that the European stock market does not Granger cause the Asian market is 8.04705. In other words, the European market Granger causes the Asian market, but the Asian market does not Granger cause the European market.

The results indicate that bi-directional causality exists between most of the stock markets, except that Europe does not Granger cause the US and the Asian market does not Granger cause the European market. This suggests that there is a substantial level of interdependence among the stock market groups. Since almost all the relationships are significant, it is difficult to make conclusions regarding the specific relationships. However, the results of the Granger tests indeed indicate a high level of interdependence, and the VAR, impulse response functions and variance decompositions will be used to analyze the specific relationships in more detail. 


\subsection{The Ordinary Least Squares Vector Autoregressive (OLS-VAR) Model}

To further the dynamics of the system, we estimate vector autoregression (VAR) models. The number of lags was chosen on the basis of the Akaike (AIC) and Schwartz (SC) criteria, and the estimation was done for the period 1967-1999. The results are given in Table 3, with t-statistics reported below in parenthesis. Significant variables (based on the cut-off value of 1.69) are indicated in bold print.

Table 3 OLS-VAR, 1967-1999, 2 lags

\begin{tabular}{|l|c|c|c|c|}
\hline & Asia & Europe & $\begin{array}{c}\text { Latin } \\
\text { America }\end{array}$ & US \\
\hline Asia(-1) & $\mathbf{0 . 8 8 8 8 6 6}$ & -0.024921 & $\mathbf{0 . 5 0 6 0 1 2}$ & $\mathbf{- 0 . 0 4 4 3 1 4}$ \\
\hline & $(3.08940)$ & $(-0.78663)$ & $(2.32994)$ & $(-1.85548)$ \\
\hline Asia(-2) & $\mathbf{- 0 . 6 9 8 9 1 5}$ & 0.024407 & -0.267701 & 0.030144 \\
\hline & $(-2.23979)$ & $(0.71035)$ & $(-1.13652)$ & $(1.16375)$ \\
\hline Europe(-1) & -1.450122 & $\mathbf{0 . 7 8 4 5 5 6}$ & -3.473493 & 0.122299 \\
\hline & $(-0.40153)$ & $(1.97292)$ & $(-1.27416)$ & $(0.40796)$ \\
\hline Europe(-2) & $\mathbf{9 . 1 4 8 6 6 0}$ & -0.018465 & 2.258657 & -0.008328 \\
\hline Latin & $(2.44511)$ & $(-0.04482)$ & $(0.79972)$ & $(-0.02682)$ \\
\hline America(-1) & -0.494690 & 0.005816 & 0.078944 & 0.010586 \\
\cline { 2 - 6 } Latin & $(-1.39917)$ & $(0.14940)$ & $(0.29580)$ & $(0.36072)$ \\
\hline America(-2) & $\mathbf{0 . 7 3 5 1 9 7}$ & 0.025967 & $\mathbf{0 . 5 8 4 7 7 5}$ & 0.028779 \\
\hline Us(-1) & $(1.85268)$ & $(0.59429)$ & $(1.95223)$ & $(0.87367)$ \\
\hline & -2.462753 & $\mathbf{0 . 2 1 6 5 8 5}$ & -0.745697 & $\mathbf{0 . 9 4 5 1 6 4}$ \\
\hline US(-2) & $(-0.62705)$ & $(0.50082)$ & $(-0.25153)$ & $(2.89911)$ \\
\hline & -2.526701 & 0.190616 & 4.069549 & 0.093593 \\
\hline C & $(-0.58108)$ & $(0.39812)$ & $(1.23985)$ & $(0.25930)$ \\
\hline & -8.399961 & -6.955426 & -184.4471 & -14.09604 \\
\hline Akaike & $(-0.05206)$ & $(-0.39153)$ & $(-1.51453)$ & $(-1.05254)$ \\
\hline
\end{tabular}

The Asian market seems to be the most vulnerable for changes in other stock markets, since it receives feedback reaction from all the markets except the US market. As explained in Section 3, the strength of the bilateral trade relationship between two countries (or groups of countries) positively influences the extent of interdependence between their stock markets. The Asian countries have extremely open economies and strong trade ties with all three the other groups. Therefore one would expect high interdependence between the Asian and other stock markets. On the other hand, the European economies are much less open 
than the Asian economies, which explain why the European stock markets are less vulnerable than the Asian stock markets.

The Asian market group also seems to be extremely influential in this system, since all the markets, except the European market, receives feedback reaction from Asia. In addition, lags in the Asian stock market influence three groups of stock markets (Asia, Latin America and the US), while lags in the European and Latin American stock markets only influence two groups each (themselves and Asia), and the US only influences itself. The fact that the Asian markets are so influential could be evidence of the so-called "Asian-contagion" effect. Chen and Zhang (1997) have shown that not only the extend of total bilateral trade, but specifically the extent of imports influences the vulnerability of one stock market to changes in another. In other words, the higher the imports from a specific country (or group of countries), the greater the influence of that country's (or group of countries') stock markets will be on the domestic stock market. This explains why the Asian stock markets are so influential, since all three other stock market groups are net importers from Asia. If the analysis was done with daily data, the leading opening times of the Asian stock markets could also explain why Asian is so influential, but this should not play a significant role when annual data is used.

Most of the feedback effects between markets are positive, except for a number of negative effects that are evidence of cyclical adjustments, which are common in VAR specifications. For example, the feedback from Asia lagged one and two periods on itself is positive and negative respectively.

\subsection{Variance Decomposition}

Once the VAR model is estimated, the dynamic responses of each of the markets to a shock in a particular market are analyzed using the simulated responses of the estimated VAR system. These dynamic simulations help to measure the relative importance of each market in generating unexpected fluctuations of returns to a particular market. This, in turn, indicates the causal ordering among the six stock markets.

The variance decomposition analysis explains the forecast error variance of returns in a particular market due to innovations in its own or a foreign market over a given horizon. The ordering was done on the basis of the relative influence that each series have on the system, as indicated by the results of the VAR model. Lags in the Asian stock market influence the Asian, Latin American and US stock markets. Lags in the European stock market influence the Asian and European markets, while lags in the Latin American stock markets influence the Asian and Latin American markets. Lags in the US stock 
market influence only the US market. Therefore the Asian market influences three markets, the European and Latin American markets influence two markets each and the US market only influences one market. On this basis the ordering was from Asia to Europe to Latin America to the US. (When Europe and Latin America were reversed, there were no significant changes in the results.) The averages of the variance decompositions for a 10-year period are given in Table 4.

\section{Table 4 Variance decompositions of the VAR model}

\begin{tabular}{|l|c|l|c|c|}
\hline \multirow{2}{*}{$\begin{array}{c}\text { Average percent } \\
\text { variation in: }\end{array}$} & \multicolumn{4}{|c|}{ Due to innovations in: } \\
\cline { 2 - 5 } & Asia & Europe & $\begin{array}{c}\text { Latin } \\
\text { America }\end{array}$ & US \\
\hline Asia & 65.55207 & 20.9565 & 4.202181 & 9.289251 \\
\hline Europe & 1.861681 & 72.55007 & 10.8073 & 14.78095 \\
\hline Latin America & 34.8441 & 28.4092 & 32.28106 & 4.465642 \\
\hline US & 11.93285 & 39.59079 & 14.9137 & 33.56265 \\
\hline
\end{tabular}

The result of this analysis highlights a number of interesting facts. Except in the case of the US most of the 10-period-ahead prediction error of each of the variables is explained by innovations in itself. On average, 65 per cent of the prediction error in Asia, 75 per cent of the prediction error in Europe, and 37 per cent in the prediction error in Latin America is explained by innovations in itself. On average, 50.8 per cent of the prediction error in the US is explained by innovations in the European market which is more than the 33.56 per cent explained by innovations in itself.

The strong interdependence between the emerging stock markets of Latin America and Asia that was indicated by the correlation coefficients (see Section 2 ) is confirmed by the results of the variance decompositions. Innovations in the Asian stock markets explain most of the forecast error variance of the Asian as well as the Latin American markets. Likewise, innovations in the European stock markets are the largest contributor towards the forecast error variance of the furopean and US stock markets. This is probably due to the self-fulfilling expectations of investors that assets in the emerging market asset class (e.g, Latin Amcrican and Asian stocks) will all behave alike, and likewise, that assets in the developed stock markets will behave similarly, as explained in Section 3.

If alnost all of the forecasting error in a series is explained by innovations in itself, it suggests that the series can be viewed as largely exogenous. The results of the variance decompositions indicate that less than half the variation in the forecasting error of any stock market group is explained by innovations in itself. 
This is evidence that the groups are interdependent, since none of them can be seen as exogenous.

\subsection{Impulse Response Functions}

Impulse responses that summarize the short-run and long-run effects of various shocks to the system are displayed in Figure 2 . The same ordering as in the variance decompositions was used.

\section{Figure 2 Impulse response functions}

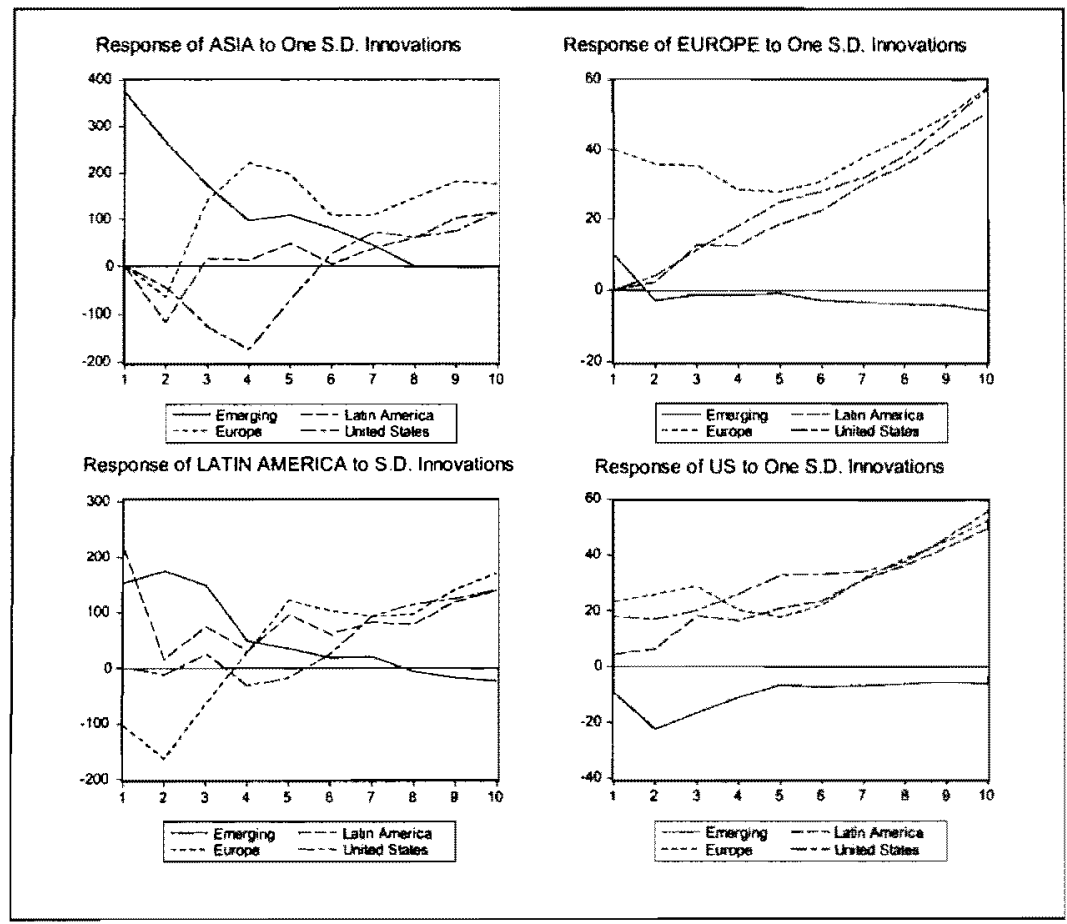

In the first graph, the effect of a shock in the Asian market on itself lasts only for 8 periods after which it converges to the long-run equilibrium level. Shocks in any of the other markets initially have a negative impact, but the effects of the European, Latin American and US markets tum positive within 2, 3 and 6 periods respectively. 
According to the third graph, Latin America's reaction on innovations in other stock markets is similar to that of the Asian stock market. Just like the Asian market, innovations in the European and US markets cause an initial decrease in the Latin American market, but within 6 periods both effects have turned positive. The effect of the innovations in the Asian market is again initially positive, but instead of converging to equilibrium after 8 periods like the Asian markets, it decreases. In general, both the Asian and Latin American markets increase after a few periods in response to innovations in the European and US markets, and fail to return to equilibrium afterwards. Both markets increase initially after innovations in the Asian market and then either return to equilibrium or decrease slightly.

The second graph shows that the European market reacts positively to innovations in any of the markets, except the Asian market, and keeps on increasing without returning to the equilibrium level. On the other hand, shocks in the Asian market cause a decrease in the European market, and again the European market does not return to the long-run equilibrium level.

Similar to the European market, the US market also decreases after a shock in the Asian market, and increases after a shock in any other market. The European and US markets are extremely susceptible to shocks, since they both react dramatically to a shock in any other market. The sharp, sustained increases indicate that these two markets have a propensity to grow positively.

The reactions of the two groups of developing countries, Latin America and Asia, are remarkably sinilar. This is evidence of the contagion effect discussed in Section 3. Investors see the developing stock markets as a single asset class, and this creates a self-fulfilling expectation that the developing stock markets react in the same way to shocks. Likewise, the developed stock markets are to some extent seen as a single asset class of assets that are safe and stable relative to the developing markets. This creates self-fulfilling expectations that the developed markets will react similarly to shocks.

\subsection{The Fully Modified Vector Autoregressive (FM-VAR) Model}

The results of the FM-VAR model are given in Table 5, with t-statistics reported below in parenthesis. The t-statistics are asymptotically valid. Significant variables (based on the cut-off value of 1.69) are indicated in bold print. The Parzen kernel with three autocovariance terms is used for the non-parametric estimation required by the FM-VAR. 
Table 5 Vector Autoregression Model estimated with fully modified estimation, 1967-1999, 2 lags

\begin{tabular}{|l|c|c|c|c|}
\hline & Asia & Europe & $\begin{array}{c}\text { Latin } \\
\text { America }\end{array}$ & US \\
\hline Asia(-1) & $\mathbf{- 1 . 7 2 3 8 7}$ & -1.91433 & -1.92799 & -1.67551 \\
\hline & $(-2.76848)$ & $(-1.20 \mathrm{E}-05)$ & $(-3.22971)$ & $(-0.01952)$ \\
\hline$\Delta$ Asia(-1) & $\mathbf{1 . 9 5 2 2 4 8}$ & 1.228926 & 1.223189 & 1.521034 \\
\hline & $(2.933149)$ & $(0.012842)$ & $(0.009464)$ & $(1.143083)$ \\
\hline Europe(-1) & 7.502776 & 0.570328 & -0.08179 & -1.4106 \\
\hline & $(0.064725)$ & $(0.590763)$ & $(-0.10106)$ & $(-0.01569)$ \\
\hline$\Delta$ Europe(-1) & -21.1874 & -12.0202 & -12.0304 & -14.2974 \\
\hline & $(-23.4803)$ & $(-0.11994)$ & $(-0.10177)$ & $(-20.6061)$ \\
\hline US(-1) & 13.88939 & $\mathbf{1 9 . 2 8 6 0 5}$ & 19.9176 & $\mathbf{2 2 . 2 0 2 7}$ \\
\hline & $(0.131008)$ & $(30.99154)$ & $(0.000125)$ & $(34.91805)$ \\
\hline$\Delta U S(-1)$ & -23.7059 & -26.4232 & -26.3262 & -30.3022 \\
\hline & $(-0.00013)$ & $(-44.2366)$ & $(-0.30655)$ & $(-0.26125)$ \\
\hline Latin & -0.37651 & -0.58523 & -0.57765 & 0.046704 \\
America(-1) & & & & \\
\hline & $(-0.00412)$ & $(-0.00474)$ & $(-0.56174)$ & $(0.054178)$ \\
\hline$\Delta$ Latin & $\mathbf{1 . 6 9 0 6 7 8}$ & $\mathbf{2 . 3 9 9 9 0 7}$ & 2.397096 & 1.8411 \\
\hline America(-1) & & & & \\
\hline & $(1.750195)$ & $(2.963587)$ & $(0.026653)$ & $(0.017355)$ \\
\hline c & -1299.89 & -1298.44 & -1305.58 & -1475.94 \\
\hline & $(-13.5771)$ & $(-11.498)$ & $(-1969.66)$ & $(0.00868)$ \\
\hline
\end{tabular}

While the OLS-VAR estimates only lagged variables, the FM-VAR estimation estimates first order lagged innovations and first order lagged variables. Therefore the results of the two procedures are not directly comparable. However, with little mathematical manipulation the FM-VAR results can be rewritten in a format that is comparable to the OLS-VAR estimation. These results are given in Tables 6 and 7 . 
Table 6 Comparison of lagged effects, 2 lags

\begin{tabular}{|l|c|c|c|c|}
\hline & \multicolumn{2}{|c|}{ Asia } & \multicolumn{2}{c|}{ Europe } \\
\hline & FM & OLS & FM & OLS \\
\hline Asia(-1) & 0.22838 & 0.888866 & -0.68541 & -0.024921 \\
\hline Asia(-2) & -1.952248 & -0.698915 & -1.228926 & $\mathbf{0 . 0 2 4 4 0 7}$ \\
\hline Europe(-1) & -13.6846 & -1.450122 & $-\mathbf{- 1 1 . 4 4 9 9}$ & $\mathbf{0 . 7 8 4 5 5 6}$ \\
\hline Europe(-2) & 21.1874 & 9.14866 & $\mathbf{1 2 . 0 2 0 2}$ & $\mathbf{- 0 . 0 1 8 4 6 5}$ \\
\hline US(-1) & -9.81651 & -2.462753 & $-\mathbf{7 . 1 3 7 1 7}$ & $\mathbf{0 . 2 1 6 5 8 5}$ \\
\hline US(-2) & $\mathbf{2 3 . 7 0 5 9}$ & $\mathbf{- 2 . 5 2 6 7 0 1}$ & 26.4232 & 0.190616 \\
\hline $\begin{array}{l}\text { Latin } \\
\text { America(-1) }\end{array}$ & $\mathbf{1 . 3 1 4 1 7}$ & $-\mathbf{- 0 . 4 9 4 6 9}$ & 1.814676 & 0.005816 \\
\hline $\begin{array}{l}\text { Latin } \\
\text { America (-2) }\end{array}$ & $\mathbf{- 1 . 6 9 0 6 7 8}$ & $\mathbf{0 . 7 3 5 1 9 7}$ & $\mathbf{- 2 . 3 9 9 9 0 7}$ & $\mathbf{0 . 0 2 5 9 6 7}$ \\
\hline
\end{tabular}

Table 7 Comparison of lagged effects, 2 lags

\begin{tabular}{|l|c|c|c|c|}
\hline & \multicolumn{2}{|c|}{ US } & \multicolumn{2}{c|}{ Latin America } \\
\hline & FM & OLS & FM & OLS \\
\hline Asia(-1) & -0.7048 & -0.044314 & $-\mathbf{0 . 1 5 4 4 7}$ & $\mathbf{0 . 5 0 6 0 1 2}$ \\
\hline Asia(-2) & -1.223189 & $\mathbf{0 . 0 3 0 1 4 4}$ & -1.521034 & -0.267701 \\
\hline Europe(-1) & $\mathbf{- 1 2 . 1 1 2 2}$ & $\mathbf{0 . 1 2 2 2 9 9}$ & -15.708 & $-\mathbf{3 . 4 7 3 4 9 3}$ \\
\hline Europe(-2) & $\mathbf{1 2 . 0 3 0 4}$ & $\mathbf{- 0 . 0 0 8 3 2 8}$ & 14.2974 & 2.258657 \\
\hline US(-1) & $\mathbf{- 6 . 4 0 8 5 9}$ & $\mathbf{0 . 9 4 5 1 6 4}$ & -809946 & -0.745697 \\
\hline US(-2) & 26.3262 & 0.093593 & 30.3022 & 4.069549 \\
\hline $\begin{array}{l}\text { Latin } \\
\text { America(-1) }\end{array}$ & 1.819446 & $\mathbf{0 . 0 1 0 5 8 6}$ & 1.887804 & $\mathbf{0 . 0 7 8 9 4 4}$ \\
\hline $\begin{array}{l}\text { Latin } \\
\text { America (-2) }\end{array}$ & $\mathbf{- 2 . 3 9 7 0 9 6}$ & $\mathbf{0 . 0 2 8 7 7 9}$ & $\mathbf{- 1 . 8 4 1 1}$ & $\mathbf{0 . 5 8 4 7 7 5}$ \\
\hline
\end{tabular}

In this type of analysis, the signs of the coefficients are more important than their magnitudes, since the magnitudes of the coefficients are usually not interpreted. We therefore focus on the signs of the coefficients in our comparison of the OLS-VAR and FM-VAR results. The coefficients of which 
the signs have changed when the model was re-estimated with fully modified instead of ordinary least squares, are indicated in bold print. Only four of the previously significant variables have different signs in the FM-VAR than in the OLS-VAR. There is more evidence in the FM-VAR of cyclical adjustments between the stock markets, which might give a more stable system. In addition, Phillips (1995) has shown that the FM-VAR is more robust when non-stationary or cointegrated series are included. However, the limited degrees of freedom make it questionable whether the FM estimates truly eliminate the OLS bias.

In this study, we used time series techniques to investigate the relationships among four of the most important groups of economies, namely Europe, Latin America, Asia and the US. Overall, we found evidence of a high level of interdependence among the stock market groups. In particular, there are a substantial amount of evidence that support the hypothesis of interdependence between the developing stock markets of Asia and Latin America, and between the developed stock markets of the US and Europe. This is probably an example of contagion, where investors group the developed and emerging markets as two asset classes, and then build self-fulfilling expectations that stocks in each of the two asset classes will behave similarly. The results suggest that diversification between developed (European and US) and emerging (Asian and Latin American) markets are still possible, even though the interdependence within these groups is so high that diversification is no longer possible.

\section{REFERENCES}

1 ASNESS, C.S., LIEW, J.M. \& STEVENS, R.L. (1996) "Parallels between the Cross-Sectional Predictability of Stock and Country Returns", Working Paper, New York: Goldman Sachs Asset Management.

2 BANZ, R.W. (1981) "The Relationship between Return and Market Value of Common Stocks, Journal of Financial Economics, 9: 3-18.

3 BERK, J. (1996) "An Empirical Re-examination of the Relation between Firm Size and Return", University of British Columbia: Unpublished manuscript.

4 CHEN, N. F., ROLL, R. \& ROSS, S.A. (1986) "Economic Forces and the Stock Market", Journal of Business, 59: 383-403.

CHOUDHRY, T. (1996) "Interdependence of Stock Markets: Evidence from Europe during the 1920s and 1930s", Applied Financial Economics, 6: 243-9. 
6 CHOUDHRY, T. (1997) "Stochastic Trends in Stock Prices: Evidence from Latin American Markets", Journal of Macroeconomics, 16: 629-51.

7 CHOWDHURY, A.R. (1994) "Stock Market Interdependencies: Evidence from the Asian NIEs", Journal of Macroeconomics, 19: 285-304.

8 CHRISTOFFI, A. \& PERICLI, A. (1999) "Correlation in Price Changes and Volatility of Major Latin American Stock Markets", Journal of Multinational Financial Management, 9: 79-93.

9 CHUHAN, P. (1994) "Are Institutional Investors an Important Source of Portfolio Investment in Emerging Markets?" World Bank, WPS 1243.

10 DHEERIYA, P.L. (1993) "Further Evidence on Causality and Feedback Across International Stocks", Journal of Economics and Finance, 17: 160-7.

11 ENDERS, W. (1995) Applied Econometric Time Series, New York: John Wiley \& Sons.

12 HANDLEY, A. \& MILLS, G. (1996) "The South African Economy in the 1990s", Johannesburg: South African Institute of International Affairs.

13 HATANAKA, M. (1996) Time-Series-Based Econometrics, New York: Oxford University Press.

14 KEPPLER, A.M. \& TRAUB, H.D. (1993) "The Small Country Effect: Small Markets be Large Markets", Journal of Investing, Fall: 17-24.

15 LINTNER, J. (1965) "The Valuation of Risk Assets and the Selection of Risky Investment in Stock Portfolios and Capital Budgets", Review of Economics and Statistics, 47: 13-37.

16 LIU, Y.A., PAN M.S. \& SHIEH, J.C.P. (1998) "International Transmission of Stock Price Movements: Evidence from the US and Five Asian-Pacific Markets", Journal of Economics and Finance, 22: 59-69.

17 PALAC-MCMIKEN, E.C. (1997) "An Examination of ASEAN Stock Markets: A Cointegration Approach", ASEAN Economic Bulletin, 13: 299-311.

18 PHILLIPS, P.C.B. (1995) "Fully Modified Least Squares and Vector Autoregression", Econometrica, 63: 1023-78.

19 PINDYCK, R.S. \& RUBINFIELD, D.L. (1991) Economic Models and Eionomic Forecasts, Singapore: McGraw-Hill.

20 ROLL, R. (1992) "Industrial Structure and the Comparative Behavior of International Stock Market Indices", Journal of Finance, 47: 3-41.

21 SERRA, A.P. (2000) "Country and Industry Factors in Returns: Evidence from Emerging Markets' Stocks", Emerging Markets Review, 1: 127-51.

22 SHARPE, W. (1964) "Capital Asset Prices: a Theory of Market Equilibrium under Conditions Risk", Journal of Finance, 19: 425-42.

23 WOLF, H.C. (1998) "Determinants of Emerging Market Correlations, in: Levich, R. (ed.) Emerging Market Capital Flows: 219-35, Great Britain: Kluwer Academic Publishers. 